\title{
Institutionalization of Social Justice and Constitutionalization of Socio-economic Equality
}

\author{
Caroline Guibet Lafaye \\ Philosophy, Centre Maurice Halbwachs $(C N R S)^{1}$
}

Liberalism, in its different forms, takes into account some positive but limited requirements of mutual assistance which, in a democratic society, are institutionalized and implemented by laws. This requirement of impartiality has been implemented by the increase of public functions of mutual assistance, by the development of the welfare State and by the social democratic alternative of liberal theory. ${ }^{2}$ However and although the liberal State tends towards a conciliation of the requirements of impartiality and of the requirements of individuality, it remains unsatisfactory. Liberal societies impose a limited impartiality, obtained by means of institutions which require of their members a specific attachment to certain rights and to certain procedures. This task is indeed easier to implement than the institutionalization of a more levelling system. However we would like to determine up to which point and in which conditions it is possible to establish rights to a social minimum in addition to the rights to fundamental liberties and to legal and political equality guaranteed to all. ${ }^{3}$ From there, it would be possible to constitutionalize the elimination of poverty, through a set of limited dispositions that the legislative and executive authorities would be legally charged to implement, through specific programmes. If these measures can escape from political bargaining and from interested calculations, a first step towards a more global socio-economic equality would be made. Thus we would like, in the following developments, to consider the conditions of a social and political system, which satisfy the requirements of impartiality more than liberalism does, even in its more equalitarian versions. In the same way, we would like to specify the means of a progressive institutionalization of socio-economic equality.

\footnotetext{
${ }^{1}$ 48, bd Jourdan, F-75014 Paris (France). Contact : caroline.guibet-lafaye@ens.fr

${ }^{2}$ Even if the great inequalities of wealth and power, within theses systems, are incompatible with a basic concern of equity. See Rosanvallon 1995, and Fitoussi and Rosanvallon 1996.

${ }^{3} \mathrm{~T}$. Nagel however suggests that the aim of a levelling system seems to be out of the reach of a constitutionnalization project of social rights.
} 


\section{1- Moral conditions for the institutionalization of socio-economic equality}

The implementation of socio-economic equality, through a legislative programme and through the ordinary methods of a democratic policy, as the "constitutionalization" of socio-economic equality, suppose an adequate division of the reasons and of the motives between the sphere of the individual, the sphere of the personnal and the sphere of the impersonal. It is necessary, on the one hand, to ensure to each one a coherent way of life, enabling her to pursue her personal goals while respecting the impersonal reasons in her public life. The institutionalization of a more levelling socio-economic system will be supported by the individuals, only if its institutions and its conventions are psychologically viable and only if these institutions produce customs, habits and practices. However the individual moral attitude, regarding policies aiming at more equality, can change, collectively, only by the development of practices, which will allow individuals to follow priorities and values which are not only personal but which will modify their perception of themselves.

A second stage of the realization of an egalitarian ideal supposes the recognition of a negative responsibility of society with regard to the inequalities, in particular, inequalities in income, wealth, social position, health, education which society allows. Deciding to defend and apply only rights associated with a system of laissez-faire constitutes a choice made by the State. It supports a system which remunerates individuals, having the strongest capacity to produce - as their heirs -, at the expense of the individuals who have a weaker capacity to produce ${ }^{4}$. The justification of such a social and political choice is based on a specific account of equalitarian impartiality. It rests on arguments in favour or against inequalities. It is thus necessary to put forward criteria and measures of justice which answer the requirements of equity and which could reduce these inequalities, while avoiding irreducible resistance from the members of the community. These principles must be able to enter within a vast plurality of individual conceptions of good life.

In this aim, it is advisable to establish institutions serving an egalitarian ideal of impartiality without requiring these institutions an excessive impartiality of individuals. This point of view, as P. Ricoeur underlines it, raises the question of knowing "up to which point the principles of justice - and singularly the second principle [of justice of Rawls] - can [...] exert the role of a guiding idea [...] in regard to justice as a social practice?". 5 In the same spirit, Joshua Cohen and Joel Rogers defended a "democratic principle of legitimacy" which would integrate, without being subjected to majority

\footnotetext{
${ }^{4}$ Then the latter are deprivated of what they could have had in another system. The State, and consequently the citizens, are responsible for this result.

5 “Jusqu'à quel point les principes de justice - et singulièrement le second [principe de justice de Rawls] - peuvent [...] exercer le rôle d'idée directrice [...] à l'égard de la justice en tant que pratique sociale?" (Ricoeur 1991: 188).
} 
revision, the requirement that the institutions satisfy the Rawlsian difference principle (see Cohen and Rogers 1983: 158-161). ${ }^{6}$ Thus the institutionalization of social justice could, for example, follow the way of a constitutionalization of the difference principle. Some substantial rules of justice, concerning for example the freedom of religion, have already been integrated in the institutions. Legal, civic and political equality, for example, are guaranteed by the Constitution and escape from the influence of human arguments and from political interference. In the same way, many constitutions of the Western industrialized countries enshrine social rights, such as rights to unemployment insurance, right to paid-holidays and right to social security. ${ }^{7}$ Consequently, one can plan to integrate in the constitution, in accordance with this model, social rights supporting a socio-economic equality. In this perspective, a specific development of the Rawlsian criterion of justice is necessary. It will give a reasonably precise idea of the institutional reforms that this criterion, for a particular institutional system, would require if it were entirely defined. ${ }^{8}$

\section{2- Difficulties associated to an institutionalization of a socio-economic equality}

Nevertheless the constitutionalization of these objectives presents several difficulties. The institutionalization of social justice, indeed, depends on the economic organization of society and, particularly, of private and public property. It also depends on tax system, inheritance, gifts and transfers of money. This means that the realization of a levelling socio-economic constitution which would integrate, by assumption, certain economic and social rights, as through a politico-legal constitution encounters difficulties. Indeed, it is not only a question of guaranteeing to all members of the society some specific rights, relatively well defined, but to guarantee to all members of the community medical care, education, decent housing, unemployment insurance, family benefits, retirement pensions and even a minimum income. Our prospect is in fact an extension of the specific rights, guaranteed to all, beyond fundamental freedoms and legal and political equality, towards a social minimum, in order to eliminate poverty, by constitutional means that the legislative and executive authorities would be

\footnotetext{
${ }^{6}$ This question and more particularly, the question of the level of a social minimum, as well as the question of proper rate of saving over time, the question of the background institutions of taxation and property, are mentioned by Rawls as belonging to the moral problems of political economy (see 1971 (ed. 2003): 234).

${ }^{7}$ In Canada there were a significant social movement aiming at adding to the constitution a "social charter which would guarantee the right to health system, social assistance and education (Kymlicka and Norman 1992: 1-2). This charter was defended by $85 \%$ of Canadians and $88 \%$ of Québécois.

${ }^{8}$ T. Pogge suggests that "Rawls's criterion can be used to design a blueprint of ideal institutions that would be perfectly just. But much more important for now is its role in the comparative assessment of alternative feasible institutional schemes" (1989: 12).
} 
legally charged to implement through specific programmes.

\section{a) Human and psychological difficulties}

The implementation of principles of equality, in a socio-economic field, involve, firstly, difficulties due to human nature and to human psychology. More specifically, these difficulties concern, personal motivation and choices, and first of all the desire to acquire. These personal reasons constrain the pursuit of a global equalitarian ideal, even if this prospect is supported by a real political design. Even within liberal societies, the most favoured individuals - i.e. not only the rich minority, but a majority of individuals who are not poor - tend to slow down the pursuit of socio-economic equality, beyond a relatively modest level. Whereas during the $\mathrm{XX}^{\text {th }}$ century in particular, attitudes with regard to racial or sexual discrimination have changed, on the other hand, social attitudes towards economic inequality, except extreme poverty, remain the same. The winners of economic competition, the heirs of a fortune or of an advantageous social position tend to think that they have been lucky or that they deserve their advantages. In the majority of cases, they do not conceive that they enjoy benefits of badly acquired profits or that they enjoy profits whose origin sullies their reputation, in particular when they are inherited advantages. The recognition of the legitimacy of a redistributive system, of which part of the contributors seem to be the victims, supposes that the holders of high incomes owe their fortune in respect to historical contingencies, much more than to their own qualities, their own choices or to their personal efforts. The way in which a person earns her money, in a competing economy, where equal opportunity is not forced by the traditional forms of discrimination, seems seldom illegitimate from the winners' point of view. It is, generally, conceived that these inequalities are justified in an external way. The recipients of this system imagine that they legitimately have natural capacities and assets, due to their education and to their social condition, and which they have exploited well. ${ }^{9}$

The creation of stable egalitarian institutions, however, requires that these attitudes change. Thus the resistance induced by the implementation of socio-economic equality can be overcome, for example, if the conventional institutional structures, which work in favour of the common and public good in a morally acceptable way, penetrate more to the heart of individual life. Thus we can suppose that the more general the common good that the political system aims to implement is, the more the pursuit of this good in particular if this good is conceived in levelling terms - will escape from the contrary influences of democratic politics (e.g. Nagel 1991: 95). In the same way, the priority given to the worst-off, in the socio-economic field, can constitute a basis for public

\footnotetext{
${ }^{9}$ The corresponding attitude, concerning advantages due to a dominant race or due to gender, is not any more acceptable nowadays.
} 
policy. This requirement can guide debates concerning social and economic policy. However these debates aim at a consensus between the partners, since "so long as there was sufficient agreement among the members of a society about the implications of social justice, these might be embodied in specific substantive rules and incorporated in the constitution" (Barry 1995: 96).

\section{b) Difficulties of an economic nature}

Moreover, the institutionalization of social justice supposes to solve economic difficulties. Economic life is narrowly dependent on incentives and economic stimulations. The realization of a structure, in which economic inequalities are reduced, must be compatible with the preservation of productivity. The legal and economic structures, able to implement, constitutionally, socio-economic equality must preserve individuality and economic efficiency. Efficiency certainly constitutes an argument which cannot be neglected. Nevertheless and from an ethical point of view, the pursuit of the greatest profitability and of the highest productivity, whatever the cost, cannot constitute a priority principle.

\section{c) Difficulties relating to the implementation of social justice}

The constitutionalization of social justice - which is a fundamental stage of the realization of socio-economic equality - must finally face difficulties related to its implementation. Indeed, it is not sufficient that an agreement between the social partners registers, in the constitution, rights ensuring social justice between all the members of the community. In fact, we can legitimately expect that there are various opinions concerning the best real social arrangement (i.e. the best calculated arrangement) and the arrangement the most able to privilege the worst-off. Rawls underlines that tax legislation and laws on property belong to the field of the "essential constitutional questions" and belong to the field of justice as equity. They are subject to a reasonable disagreement, concerning the implications of principles of justice. ${ }^{10}$

In the same way, B. Barry suggests that social justice is not able to determine the

${ }^{10}$ In a theory of justice, it is the only source of authorized indetermination. Rawls stresses that "the question whatever legislation is just or unjust, especially in connection with economic and social policies, is commonly subject to reasonable differences of opinion. [...] Often the best that we can say of a law or policy is that it is at least not clearly unjust. The application of the difference principle in a precise way normally requires more information that we can expect to have and, in any case, more than the application of the first principle" (1971: 174). There is nothing incoherent here with the assessment that the principles of justice must leave open a fair result, in a more radical way. The main difficulty consists in applying the difference principle, that is to decide which laws and which policies would be, actually, most advantageous, in terms of primary goods for the worst off group. 
level or organisation of health, education or social security provision. In the modern societies, social justice requires that all the requirements related to these fields be satisfied. Nevertheless variations and modifications are possible. ${ }^{11}$ In spite of the mobility of labour and capital and in spite of the free exchange of goods and services, collective decisions can be made about laws concerning the security of employment, environment and social wages.

It is true, however, that the concept of social justice cannot establish, by itself, a single response to the encountered difficulties. Indeed, there is no conventional element of agreement able to determine the distribution of income and the distribution of health care, for example. In the case of public services, it can be admitted that justice concerns, initially, the way in which funds are obtained and the way in which services are distributed between the potential beneficiaries. However the level of the expenditure depends, to a certain extent and legitimately, on what citizens agree to pay for, that is, it depends on the "willingness to pay". ${ }^{12}$ Brian Barry suggests that if we do not attribute to the courts of justice the interpretative authority of the difference principle - or of any other principle of distributive justice - it seems difficult to imagine a specific formula, establishing a progressive taxation on incomes or an inheritance tax, that can be set in constitution. ${ }^{13}$ Thus and even if the difference principle would sustain a broad consensus, it appears that its concrete implementation will cause dissension.

\section{3- Circumstances of impartiality}

However, these conflicts can be avoided under several conditions. They depend, in particular, on the conditions of the decision-making processes and of the selection of the principles of justice. Indeed the procedures best able to encourage just laws and fair policies are those which respect the conditions of the original position described by Thomas Scanlon. ${ }^{14}$ This original position supposes that people are well informed, pursue their own interests and their own conception of the good, but are able to

\footnotetext{
${ }^{11}$ For example the French people can choose to privilege education instead of pensioners, whereas the Germans can decide to support the retirements while being less generous in regards to education. These divergences reflect collective preferences and distinct social choices.

${ }^{12}$ See B. Barry analysis concerning the expertise on the value, starting from the implementation of the Contingent Valuation Method (CVM) founded on the "willingness to pay" (WTP) and the "willingness to accept" (WTA) (1995: 153 and sqq.).

${ }^{13}$ The courts of justice can intervene to implement principles of social justice. However, they cannot initiate governmental programs nor have a systematic sight on governmental policies neither. This practical problem is not the only one. The achievement of social justice aims implies expenditure. However the courts of justice have not the capacity to control the budget distribution neither to orientate tax allocation nor to make decisions regarding the level of expenditure, within a country or a State.

${ }^{14}$ See Guibet Lafaye 2005: ch. 3.
} 
recognize and acknowledge the reasonable objections formulated by others. The institutional framework guarantees equality between the partners. Each one has a right of veto on the proposals which he cannot reasonably reject. The hypothetical conditions thus described draw the circumstances of justice. Thus "we may define the circumstances of impartiality as the conditions under which the substantive rules of justice of a society will tend actually to be just" (Barry 1995: 100). ${ }^{15}$ Indeed the circumstances of impartiality not only lead to justice but are, in themselves, intrinsically fair. They describe the conditions under which a principle of justice can be applied.

Within the conditions able to produce a broad disposition that can accept the force of reasonable objections, we can add to these circumstances of justice the requirement to hold the citizens equal, in a fundamental sense. This principle allows that an objection can never be rejected, for the sole reason that it was formulated by a member of a minority (see Barry 1995: 102-103). In a situation where all the participants are well informed and where their interests are expressed with the same force, a good argument does not depend on the social identity of its defender. Equity is respected when the process aims and leads to a consensus. On the other hand, when this consensus is not possible, each partner is equally treated, if a voice in a vote is granted to her, for example. However this condition is not sufficient.

It is also necessary - and this is an additional condition - to establish a policy, such that the arguments are weighted and in which the best argument win, rather than a policy where only count the votes and the majority vote. Each participant must be able, within this process of decision-making, to defend his own conception of the good and to convince the others that their conceptions, well understood, amount to the same position as his position. In this way we can also consider the manner in which public policies can be provided, in a neutral way, in comparison with the various conceptions of good life. ${ }^{16}$

Incontestably, there are also precise rules of decision, specifying the way in which the election of a Parliament or a voting procedure for legislation within the Parliament must proceed. Governmental laws and governmental policies cannot be respected and have validity only if they result from a process of "open justifications openly arrived at" (Macedo 1991: 69). ${ }^{17}$ Legislation, for example, must be founded on a process of consultation, during which the individuals and the groups concerned have sufficient time to formulate proposals and comments, sufficient time to be heard and to take part

${ }^{15}$ The concept of "rules of justice" gives here an account of moral rules as well of legal rules.

${ }^{16}$ See Barry 1995: 143. This interpretation of a field of neutrality was advocated by R. Dworkin and criticized by Joseph Raz (1986: 110-162), Jeremy Waldron (1989: 61-83), and Stephen Mulhall and Adam Swift (1992: 29-32 in particular). Although Dworkin recognized the requirement of such a field, he did not demonstrate, in a precise way, how public policies could be followed while respecting the neutrality of procedures. The arguments used in favour of allowances indexed on the resources (i.e. rights, money, etc.) rather than on utility, are related to the distribution of private goods (Dworkin 1981a and 1981b).

${ }^{17}$ Consequently social justice is guaranteed in the framework of such procedures. 
into the process of rational evaluation. A law which results from this procedure is justifiable and can be actually defended. Thus these requirements - which are empirical - concern the procedure more than the substantive and positive principles of justice. Nevertheless, when they are respected, there is a lower likelihood of ending up with unjust legislation than when these requirements are not respected. The constitutional requirements, the institutions of education, the organization of mass media and of communication provide the conditions under which the decisions taken respect the circumstances of impartiality. Thus the possibility of guaranteeing social justice rests on the circumstances of impartiality. In a general way, "a just constitution must be set up in such a way that all decisions are taken in ways that instantiate the circumstances of impartiality" (Barry 1995: 110).

However as Rawls underlines it, public reason works as a norm of impartial justification, whose limits concerning the decision-making process "do not apply [however] to all political questions but only to those involving what we called the 'constitutional essential' and questions of basic justice" (Rawls 1993: 204; see also § 5). By contrast, much tax legislation and many laws regulating property, statues protecting the environment and controlling pollution, establishing national parks and preserving wilderness areas and animal and plant species, and laying aside funds for museums and arts do not belong to these fundamental matters. Thus Rawls distinguishes two kinds of objects. The first - tax legislation and laws on property - belong to the field of justice as equity but are subject to a reasonable dissension, concerning the implications of principles of justice. The second category of objects - i.e. the rest of the list - concerns questions which cannot be solved without giving priority to one conception of the good rather to another. The requirement of impartial justification is satisfied, in this case, only if the procedure, in accordance with which decisions are made, is fair and if the policy is fairly accomplished. Thus the taxes financing public expenditure must be raised according to fair methods. Indeed, against such measures - or against all other policies -, one cannot maintain the fact that this disposition is appropriate for those which defend such conception of the good, but not for those which defend another conception of the good. It is thus necessary to require that the procedures by which decisions of courts - and, more generally, decisions concerning the social context respect the fairness of the decision process. When justice exists, the fairness of the procedure adds a value to that which the fair and impartial decision has by itself. Even when the decision taken would be perfectly just, it is essential that the method by which the decision is taken is not unjust or inequitable. Indeed, when people are not satisfied with a decision, they are nevertheless more able to accept it, if this decision was taken at the end of a fair procedure. ${ }^{18}$ When the justice of a decision is doubtful - as it is often

\footnotetext{
${ }^{18}$ By hypothesis we are in presence of conflicting conceptions of the good. The individuals cannot thus assert that the adequate criterion, within several principles of justice, is the one which manages the best to carry out the good. Consequently "where justice is unavailable to provide the basis of
} 
the case - the equity of the procedure which conduces to it makes it more acceptable. Within the framework of a convenient original position, fair procedures will be allowed, not only because they lead to just decisions but also because the equity of the process, leading to these decisions, will make them more acceptable. In many cases, justice as impartiality can specify that the decision must be made in accordance with a fair procedure.

In this way the conditions under which a political system can introduce measures contributing to an institutionalization of socio-economic equality are specified. Indeed principles of justice and political decisions, which respect the requirements of impartiality and thus reflect their neutrality, could satisfy the conditions of an integration of the just within a plurality of conceptions of the good life and also satisfy the citizens' requirements for principles of social justice. These principles suppose, in particular, that the rules implemented in the decision-making process should not favour any particular conception of the good - against other conceptions - nor should they be defended by appealing to any other particular conception of the good.

The realization of a greater social justice within our institutions would require a specification of the transition which would lead towards fairer social institutions. In this way we will contribute to the reform of existing social institutions so as to render them more just. It will, secondly, help to improve the situation of the worst-off. This transition will finally require us to accept certain constraints upon our conduct and policies. ${ }^{19}$ The implementation of a project of social justice requires a reflection about the existing social institutions, the roles and functions involved in these institutions, taken as a single system. This reflection will allow the identification of feasible alternative systems, by taking into account the social context in which we nowadays act. It seems, however, that the most plausible approach to an institutionalization of social justice is to proceed by a constitutionalization of the difference principle.

agreement, we cannot hope to find consensus on the basis of any other substantive criterion". On the other hand one can suppose that in an adapted original position, people will be concerned by the accuracy and the equity of the procedures of decisions-making. "Generalizing the point, we may say that, where substantive justice falls short, the search for agreement has to be pushed up to the procedural level" (Barry 1995: 109-110).

${ }^{19}$ This is our own responsibility in front of the existing injustices and this shall not depend on whatever an institutional system entirely just is feasible or not. 


\section{Bibliography}

\section{Books:}

Barry, B., 1995, Justice as Impartiality, Clarendon Press, Oxford.

Cohen, J., and Rogers, J., 1983, On Democracy, Penguin Books, New York.

Fitoussi, J.-P., and Rosanvallon, P., 1996, Le nouvel âge des inégalités, Seuil, coll. Essais, Paris.

Goodin, R. E., and Reeve, A., ed., 1989, Liberal Neutrality, Routledge, London.

Guibet Lafaye, C., 2005, Justice et vie bonne. La justice comme composante de la vie bonne, Presses Universitaires de Laval, Sainte-Foy.

Macedo, S., 1991, Liberal Virtues: Citizenship, Virtue, and Community in Liberal Constitutionalism, Oxford University Press, Oxford.

Mulhall, S., and Swift, A., 1992, Liberals and Communitarians, Blackwell, Oxford.

Nagel, T., 1991, Egalité et partialité, PUF, Paris.

Pogge, T., 1989, Realizing Rawls, Cornell University Press, Ithaca and Londres.

Rawls, J., 1971, Theory of justice, Harvard University Press, Harvard, 2003.

Rawls, J., 1993, Political Liberalism, Colombia University Press, New York.

Raz, J., 1986, The Morality of Freedom, Clarendon Press, Oxford.

Ricoeur, P., 1991, Lectures I. Autour du politique, Seuil, Paris.

Rosanvallon, P., 1995, La nouvelle question sociale, Seuil, Paris.

\section{Articles:}

Dworkin, R., 1981a, What is Equality? Part 1: Equality of Welfare, Philosophy and Public Affairs 10: $185-246$.

Dworkin, R., 1981b, What is Equality? Part 2: Equality of Resources, Philosophy \& Public Affairs 10: 283-345.

\section{Contributions to a volume:}

Kymlicka W., and Norman, W., The Social Charter Debate: Should Social Justice Be Constitutionalized?, in: Network Analyses: Analysis n², January 1992, Network on the Constitution, eds., Ottawa (Canada).

Waldron, J., 1989, Legislation and Moral Neutrality, in: Goodin and Reeve 1989, pp. 61-83. 